\title{
Expanding and Improving the English Language and Culture Education of Ukrainian Tertiary Students Majoring in English
}

\author{
Oleg Tarnopolsky \\ Department of Applied Linguistics and Methods of Teaching Foreign Languages, Alfred Nobel \\ University, Dnipro, Ukraine \\ otarnopolsky@ukr.net
}

\begin{abstract}
Keywords: tertiary students, English as major, English in the context of international communication, specific features of the English language and culture education, a course on specific features of the English language and the cultures of English-speaking nations, master degree level of English studies.
\end{abstract}

\begin{abstract}
The article discusses an innovative course taught to students majoring in English at Ukrainian universities. The course called "Specific Features of the English Language and EnglishSpeaking Nations' Cultures in the Context of International Communication" was designed to eliminate the lack of a number of issues that must be included in the curriculum of English language and culture studies to be learned by such students but which are ordinarily not included there because each of them cannot make the subject matter of a separate university course and does not fit into the traditionally taught courses. The issues in question embrace: the specific (global or planetary) role of English among other languages of international communication; World Englishes, International English and English as a lingua franca and how to choose the variety of English to be taught as a foreign language; the specifics of business negotiations in English in intercultural contexts, business presentations in English, and business telephoning in English in such contexts; communicative behavioral etiquette (verbal and non-verbal) in intercultural communication in English; lifestyle communicative behavioral patterns of the English-speaking nations. The paper shows how teaching these issues enriches and improves the English language and culture education of English major students expanding that education and relevant practical training to fit much better the international and intercultural contexts of communication in English.
\end{abstract}

\section{Introduction}

Ukrainian universities training students majoring in English (future teachers of English, translators, interpreters, and applied linguists), as a rule, ensure the acquisition by learners of highlydeveloped English communication skills, quite a sufficient mastery of English grammar, vocabulary, and phonetics, as well as the language system in general. English culture is also taught rather extensively. But it should not be forgotten that culture is a many-sided phenomenon. It certainly includes literature, art, history of the people, legislation, forms of government, etc. - the so-called culture with a big "C". Mostly this culture is taught to university students majoring in English. But such a kind of culture has very little impact on communication if it is not communication on the issues of literature, art, law, and other culture with a big " $\mathrm{C}$ " matters. However, there is a different culture (culture with a small "c") having the greatest influence on human intercourse, so that the latter is almost totally dependent on the former. What this specific culture means was defined as far back as the 1950s in the famous book by Lado [1]. He, exploring the relation between language and culture and being interested only in those aspects of culture that directly influence communication in a given language, wrote that culture is a patterned behavior. What this means will be explained in greater detail in the body of the article but here it may be safely stated that just such a type of culture is very little, or, at least, absolutely insufficiently, taught to Ukrainian tertiary students majoring in English. As a result, they have very vague ideas about the standard behavioral etiquette (verbal and nonverbal) [2] in communication in English, not infrequently making such communication culturally and socially inadequate. In what concerns culture with a small "c," students also have unclear notions as to the so-called "lifestyle communicative behavioral patterns" [3] of the English-speaking nations, 
i.e. how to do the simple everyday things while staying or living in the countries where English is spoken as the primary language (see in the body of the article), and that is often the cause of serious cultural shocks and problems.

Students majoring in English usually know some facts about the differences in the British and American varieties of the English language (though this knowledge is mostly quite elementary and absolutely insufficient for those who specialize in the relevant field). But they know next to nothing about the other recognized varieties of the English language - the so-called World Englishes [4], which is unacceptable for specialists in the language. Moreover, they have no idea about the International English [5] or English as a lingua franca [6] which are now at the forefront of attention and research of all the English language-teaching community.

Business communication in English is extremely important in today's world and students majoring in English must be thoroughly prepared for it because they will inevitably have to take part in it, if not as businesspeople proper, at least, as translators and/or interpreters. But students are mostly not prepared for it well enough. They are usually taught Business English, though rather summarily, but they are hardly ever or little taught how to conduct business negotiations $[7 ; 8]$, how to make business presentations [9], or how to do business telephoning [10] in English. As a result, they are often almost helpless in situations where their professional duties make them participate in such negotiations, prepare and deliver such presentations, or do such telephoning.

Students certainly know that English is a language of international communication. But they do not have a clear idea that is not a single international language, there are others, among which English occupies quite a specific place, and, as future specialists, they should have a clear-cut notion about all the specificities of that position and their implications for teaching and learning English as a foreign language.

A number of other, less important issues, can be listed that students majoring in English should thoroughly understand and learn. But even if those issues shortly discussed above are added to the English major curriculum, the English language and culture training of future specialists will be much improved and their language and culture education much extended in scope.

Regretfully, doing this encounters a number of practical problems and difficulties. The issues in question often cannot be included into any existing traditional courses because, as a rule, they do not match their subject matter. Considering each of them in a separate course does not seem reasonable because they do not need enough learning time to justify the elaboration of any such separate course. For instance, discussing the specific position of English as an international language among other international languages may need not more than one or two classes, the same concerns analyzing World Englishes or International English/English as a lingua franca, etc.

The only possible way out seems to be developing a synthesized course devoted to teaching all the issues mentioned above in one single framework. The course should better be designed for the master degree studies of Philology students majoring in English because the course in question is required for "fine-tuning" of English language and culture education of such students, i.e. for the final stages of their university training.

The goal of this article is discussing such a course developed by us, analyzing its structure, composition, content matter, and methods of teaching.

\section{The goal, Structure, and Composition of the Synthetic Course on Some Specific Features of the English Language and English-Speaking Nations' Cultures in the Context of International Communication}

The course "Strategies of Communication in English in the Aspect of Applied Linguistics" [11] (later renamed more adequately "Specific Features of the English Language and English-Speaking Nations' Cultures in the Context of International Communication") was elaborated for the master degree students of Applied Linguistics (the $1^{\text {st }}$ and $2^{\text {nd }}$ semesters of their master degree studies) at Alfred Nobel University in Dnipro, Ukraine; and it was first actually taught in 2018. The course was developed for 56 academic hours of class work: 28 two academic hour-long classes - with 14 two academic hour-long lecture classes and 14 two academic hour-long practical classes/seminars. 
Ninety-four academic hours were allocated for students' autonomous out-of-class studies, including their preparation for practical classes and seminars, and 20 hours - for the so-called individual work meaning learners' preparation of individual creative tasks with the results of their completion to be reported during practical classes/seminars.

The goal of the course was to expand and improve the English language and culture education of master level Philology students majoring in English by synthetically teaching them those aspects of the English language and English-speaking nations' cultures that are not and cannot be included into traditional language and culture instruction given to such students.

As to its content, subject matter, and composition, the course was divided into five main parts:

1. The Introductory part of one lecture and one seminar treating the issue of the specific place of English among other languages of international communication;

2. The part (about one-fourth of the course) devoted to the issues of World Englishes and the existing varieties of English, the principal differences between American and British English, between International English and English as a lingua franca, and the issue of choosing the variety of English to be taught as a foreign language;

3. The part (about one-fourth of the course) devoted to specifics of Business English in international communication: conducting business talks in English, preparing and delivering business presentations, talking over the telephone in English when maintaining international business contacts;

4. The part (about one-fifth of the course) devoted to the interdependence of language and culture (culture with a small "c"), language and behavioural etiquette in intercultural communication conducted in English;

5. The last part (a little more than one-fourth of the course) interpreting the issues connected with lifestyle communicative behavioral patterns of the English-speaking nations.

Each of these parts of the course merits a short description of not only its content but also of how that content is taught.

\section{The Introductory Part of the Course}

The two academic hour-long lecture on the topic "International languages of communication and the role of English as a planetary language of communication" emphasizes that English is not the only existing international language. There are others, such as Spanish, French, German, Arabic, and, to a lesser degree, Russian. The growing role of Spanish as the second, most spread, language of international communication is stressed. At the same time, it is demonstrated that all these international languages are different from English in one very important aspect. Their international spread is limited and conditioned only by the historically established ties between countries and nations. For instance, French maintains its international status exclusively because, besides France, it is spoken in the French-speaking regions of Switzerland, Canada, and in the former French colonies like Algeria, i.e. its international status is the result of historically developed ties but it enjoys such a status in a limited number of countries. Unlike that, English is used as the language of international communication by all the nations of the world, even those that have never had any close historical links with the English-speaking nations, i.e. the scope of its use for international communication is unlimited embracing the entire planet. This is why English should better be called not an international but a planetary, or global language of communication [12].

The two hour-long seminar held on the basis of the above lecture is devoted to students' presentations and discussions. They prepare those presentations after Internet-search done as a home task. That task presupposes learners' finding information about different international languages, their use and spread, and the historical causes of their acquiring the international status. Special attention is paid to the causes of English becoming a planetary language of communication and the specificity and consequences of just this status. All the students' presentations (on different topics assigned by the teacher) are not simply listened to but thoroughly discussed by the entire class with drawing appropriate conclusions. 
Therefore, it may be said that the seminar in the introductory part of the course is based on experiential learning, i.e. learning that models extra-linguistic reality, ensuring that students experience their personal functioning in that modeled reality using the target language for such functioning $[13 ; 14 ; 15]$. Internet-search on sites in the target language, preparing and delivering presentations in that language, and students' discussions are typical experiential learning activities in a foreign language course [14], and the principal advantages of their use in such courses is that they make learning active, constructive, conversational, and reflexive [16], also providing for involuntary, implicit, and almost effortless acquisition of learning material [14]. As it will be shown further, all non-lecture part of our course is based on students' experiential learning, and even lectures are made as interactive as possible making students themselves make conclusions from what they hear, thus bringing those lectures closer to experiential learning activities.

\section{The Part of the Course Devoted to the International Varieties of English}

The lectures in this part of the course focus on B.B. Kachru's [4] theory of World Englishes with the differences of Englishes in the inner circle, outer circle, and expanding circle countries. Ukraine is shown to be one of the expanding circle countries in what concerns teaching, learning, and use of the English language there. From the point of view of Kachru's theory, the inner circle (native speakers') varieties of English are discussed with special attention paid to the British and American varieties as the most developed, spread, and popular for teaching and learning in the expanding circle countries. The recent approach to teaching and learning English as a foreign language is considered. This approach presupposes teaching not one of the native-speakers' varieties of English but the socalled International English or English as a lingua franca - special simplified varieties of the language to be taught both to non-native speakers and native speakers as the only and most convenient means of international and intercultural communication. Differences and similarities between International English and English as a lingua franca are considered. It is demonstrated that the idea of teaching International English/English as a lingua franca as a foreign language is very promising but not feasible to be put into international English language teaching practice as yet. The reason is that to be taught internationally such a simplified variety of the language must be internationally codified so that in all the countries one and the same variety of International English or English as a lingua franca is taught. Until such international codification has been achieved, there is no other choice but to choose for teaching and learning one of the national (native speakers') varieties of the English language. A conclusion is drawn that it can be only British or American variety because only these two varieties are used in today's world for international and intercultural communication. It is also shown that in the condition of tertiary education in Ukraine when English is taught as a majoring subject, both British and American varieties of the English language should be taught equally thoroughly, and a specific methodology is outlined for achieving successful teaching of both varieties of English when training Philology students with English as their major [17].

All the lectures are highly interactive, and the seminars in this part of the course, like in the Introductory part, are also taught using such experiential learning activities as students' Internetsearch, presentations and discussions. But in practical classes the list of those activities is greatly expanded. Brainstorming and case studies [14] are used when students complete the tasks of transforming a text written in British English into American English or vice versa. Project work [14; $18]$ is done by small groups of students who do Internet-search, discuss, and, finally, report in class the results of their findings concerning the changes that should be introduced into one of the national varieties of English to make it suits the requirements to becoming International English or English as a lingua franca. Finally, all the work done by learners on this part of the course is summarized in their written essays, reports, abstracts, summaries, and even short articles - all these also being experiential learning activities. In this way, the experiential constituent in the part of the course under discussion is further reinforced in comparison with the preceding part. 


\section{The Part of the Course Devoted to Specifics of Business English in International Communication}

As it is clear from what is said in the Introduction to this paper, the third part of the course is devoted to specifics of conducting business negotiations in English, preparing and delivering business presentations, and talking over the telephone in English when maintaining international business contacts.

The three lectures in this part are treating the issues of the three topics mentioned above - one lecture for each of the topics. In each of the lectures several questions are discussed:

1. The structure, composition, sequence, explicit and implicit rules of business negotiations, business presentations, and business telephone talks in English;

2. Language peculiarities of business negotiations, business presentations, and business telephone talks in English;

3. Cultural peculiarities of conducting business negotiations, delivering business presentations, and holding business telephone talks in English;

4. Taking account of cultural peculiarities of your counterparts/partners who are non-native speakers of English when conducting business negotiations, delivering business presentations, and holding business telephone talks in English (as examples cultural peculiarities of dealing in business with Japanese, Chinese, Arab, German, and French counterparts/partners are analyzed).

In the practical classes/seminars students' Internet-search for additional information, their inclass presentations of their findings, and discussions of those findings are maintained. The same concerns case studies when students discuss some examples given to them (excerpts from business negotiations, business presentations, and business telephone talks in English) for finding faults in what concerns the language used, patterns employed, cultural norms broken, etc. What also remains are short learning projects, such as developing an outline of a business presentation, or a plan of conducting business negotiations on organizing a joint venture, or preparing notes for an important business telephone conversation on a given topic.

A new type of experiential learning activity used in practical classes in this part of the course is role play/simulation activity $[14 ; 19 ; 20 ; 21]$. Students role play/simulate business talks, business telephone conversations, and business presentations in the situations and in accordance with the tasks outlined by the teacher who also gives learners all the required factual information to hold a telephone conversation or a business talk spontaneously. Thus, a new experiential learning activity is included into the list of those that were used in the course previously - extending the range and scope of those activities.

Just like in the preceding part of the course, all the work done by learners is summarized in their written essays, abstracts, and summaries.

\section{The Part of the Course Devoted to the Interdependence of Language and Culture, Language and Behavioural Etiquette in Intercultural Communication Conducted in English}

This part of the course and the following, last, one is entirely devoted to cultural issues.

The lectures in the fourth part of the course discuss the dependence of communication in any language on the cultural (and social) norms existing in a given speech community [22], explain the place and role of sociocultural competence within the communicative competence of a native or nonnative speaker of English, interpret the notion of etiquette in communication dividing that etiquette into the language and behavioral one. The language etiquette regulates the peculiarities of verbally expressing one's ideas in English, so as not to break any social and cultural norms existing among educated representatives of English-speaking nations (for instance, such norms are broken if in a formal discussion one interlocutor tells another one: "You are wrong!" - unlike Russian or Ukrainian, in English disagreement should be formulated in a milder, more courteous, and more roundabout manner, e.g.: "I agree with you up to a point, but on the other hand ..."). The behavioral etiquette regulates the non-verbal behavior of communication participants so as to make this behavior 
culturally and socially adequate. Thus, the non-verbal behavioral etiquette regulates the culturespecific use of gestures, facial expressions, and gesticulation in general, the standard distance between interlocutors in communication ("the zone of comfort" or "the body bubble" which is different for different cultures) and the acceptability or unacceptability of touching your interlocutors, the norms of behavior in public places, which are also culture-specific, etc. [23]. If the language (verbal) etiquette of international and intercultural communication conducted in English is mostly the one characteristic of English-speaking nations, the non-verbal behavioral etiquette often reflects the cultural norms specific to the home cultures of participants in communication. The same concerns structuring such communication (for instance, discussing business matters with an Arab counterpart, you should not get down to business at once, which may be considered impolite and disrespectful; quite a lengthy "small talks" is supposed to precede business talks proper). Numerous examples of such "non-English" cultural deviations from the cultural and social communication patterns characteristic of English-speaking nations are also given in the lectures.

The practical classes/seminars in this part of the course include all the above-mentioned experiential learning activities: Internet-search, brainstorming, discussions, case-studies, presentations, role plays/simulations, project tasks, summarizing and discussing in writing what has been learned. But a more prominent place is occupied by case-studies when a teacher describes a case of disrupted international/intercultural communication in English and the students are asked to decide what etiquette norms of communication were broken which entailed communication disruption. Individual students are also requested to develop similar cases and submit them for discussion and solution to the other students in the group. This makes the experiential learning methodology used in the practical component of the course even more task-based [24, 25], i.e. problem solution-oriented.

\section{The Last Part of the Course Interpreting the Issues Connected with Lifestyle Communicative Behavioral Patterns of the English-Speaking Nations}

In the lectures to this part of the course lifestyle communicative behavioral patterns are treated as one the most important parts of everyday communication culture. Such patterns are defined as "... standardized patterns used by individuals to obtain specific services from social institutions designed for rendering such services in communication with either human or mechanical representatives of these institutions" [3, p. 23]. They concern doing simple everyday things such as eating out, shopping, providing oneself with accommodation, using public transport, and a number of others. In Englishspeaking countries, such as the USA or UK, a lot of such things are done in quite a different manner in comparison to Ukraine, so the students who major in English most certainly must learn how to do them there properly in order to function adequately and not to suffer from a cultural shock if they come to stay in those countries for any lengthy period of time (several months and longer). For instance, Ukrainian students do not know how to write out checks (which they will need to do if they rent a room or an apartment for the period of their stay); they have no idea about the tipping customs in the USA or UK; using American buses or Metro rail service may cause them great difficulties if they do not know in advance how to do that. It is to eliminate those and similar problems (which are the problems of everyday communication and survival) that the last part of the course is designed for.

The interactive lectures included into this part of the course consider the following lifestyle communicative behavioral patterns spread in English-speaking countries and most important for comfortable and unproblematic stay and survival thereof a visitor from Ukraine who has come to study or work in one of those countries for a more or less lengthy period of time (from one-two months and longer):

1. Lifestyle communicative behavioral patterns in financial matters when staying in English speaking countries;

2. Lifestyle communicative behavioral patterns in using public transport when staying in English speaking countries;

3. Lifestyle communicative behavioral patterns in housing when staying in English speaking countries; 
4. Lifestyle communicative behavioral patterns in eating out when staying in English speaking countries;

5. Lifestyle communicative behavioral patterns in shopping when staying in English speaking countries;

6. Lifestyle communicative behavioral patterns when travelling around English speaking countries.

The practical classes/seminars in this part of the course are designed almost exactly as in the preceding part with the dominance of case-studies considering the everyday situations where different lifestyle communicative behavioral patterns earlier brainstormed, presented, and discussed by students are used in communication practice. What differs from the practical classes/seminars from the preceding part is the absence of project work (the learning information being processed is too factual and practical for developing a project) and the use of much more role plays because the situations where lifestyle communicative behavioral patterns are used are much more propitious for roleplaying them. The Internet-search done by students and their completion of summarizing written assignments remain just as in the preceding parts of the course.

The course as a whole ends with students writing an essay on one of the topics studied (random and blind choice of the topic).

\section{Conclusion}

The course of the discipline "Specific Features of the English Language and English-Speaking Nations' Cultures in the Context of International Communication" designed for master degree studies of Ukrainian tertiary students majoring in English and discussed in this article is unique and innovative both in its contents and in methods of study.

The uniqueness of the course contents is due to the fact that the materials of the course embrace what is not included into any other courses designed for both bachelor and master degree students majoring in English. The issues of English as the planetary language of international communication, of World Englishes, International English and English as a lingua franca, and of choosing the variety of English to be taught as a foreign language; the questions of specifics of Business English negotiations in English, business presentations, and talking over the telephone in English when maintaining international business contacts; the problems of cultural dependence of communication in English and language and behavioural etiquette in intercultural communication conducted in English, as well as the issues connected with lifestyle communicative behavioral patterns of the English-speaking nations - all these are the things that English major university students should obligatorily know but which they most often do not know because there is no place for relevant information in standard university courses of disciplines for such students. Thus, in its contents the course just discussed covers the gaps existing in English language and culture education of Ukrainian English major tertiary students, significantly extending and improving that education.

The course is also unique and innovative in the methodology of teaching and learning it by students as it is entirely based on experiential task-based method allowing for learners to acquire the materials involuntarily, subconsciously, and with much less efforts through such learning activities as role plays/simulations, brainstorming, case-studies, discussions, presentations in the target language, project work, completing creative written assignments, doing Internet-search, etc.

The course analyzed in this article has been taught at Alfred Nobel University in Dnipro, Ukraine for one year only so it is rather early to make final conclusions. But the preliminary results of teaching the course are very positive which is testified by a high level of master degree students' interest, their highly positive learning motivation, and (what is quite objective) by their high learning outcomes when $80 \%$ of learners receive A grades after finishing to study the course while all the others' grades are not lower than Bs. It means that the course in question should be further developed and improved and more broadly introduced into the teaching practice when training Ukrainian university students majoring in English. 


\section{References}

[1] R. Lado, Linguistics Across Cultures: Applied Linguistics for Language Teachers. Ann Arbor (MI): University of Michigan Press, 1957.

[2] O. Tarnopolsky, Teaching etiquette communicative behavioral patterns to students of English as a foreign language. ATLANTIS. Revista de la Asociación Española de Estudios AngloNorteamericanos. 23(2) (2001) 105-117.

[3] O. Tarnopolsky, N. Sklyarenko, Lifestyle Communicative Behavioral Patterns in the USA, Second edition, revised and expanded, Kyiv: INKOS, Ukraine, 2003.

[4] B.B. Kachru, The Alchemy of English. The Spread, Functions and Models of Non-Native Englishes, Oxford: Pergamon Press, 1986.

[5] V. Cook, Going beyond the native speaker in language teaching, TESOL Quarterly. 33 (1999) 185-210.

[6] J. Jenkins, ELF at the gate: The position of English as a lingua franca, The European English Messenger. 13(2) (2004) 63-69.

[7] L.M. English, S. Lynn, Business Across Cultures: Effective Communication Strategies. White Plains, NY: Longman, 1995.

[8] E. Lites, K. Thorpe, English for Global Business. Ann Arbor: The University of Michigan Press, 2001.

[9] O. Tarnopolsky, Y. Avsukevich, Successful Presentations. A Coursebook on Business Presentations in English for Tertiary Students of Economics, Kyiv: Lenvit, Ukraine, 2007.

[10] B. Dingen, "Down to Business". English for the Telephone. Falcon Press SDN BHD, 2001.

[11] O.B. Tarnopolsky, M.R. Kabanova, P. Bradbeer, Communicative Strategies of Communication in English in the Aspect of Applied Linguistics: The Notes of Lectures. Electronic edition, Dnipro, Ukraine, 2018.

[12] D. Graddol, English Next. Why Global English May Mean the End of English as a Foreign Language. British Council, 2006.

[13] V. Kohonen et al., Experiential Learning in Foreign Language Education. New York: Routledge, 2014.

[14] O. Tarnopolsky, Constructivist Blended Learning Approach to Teaching English for Specific Purposes, London: Versita, 2012.

[15] O. Tarnopolsky, Constructivism in ESP teaching at Ukrainian universities, in: J.I. Liontas (Ed.), TESOL Encyclopedia of English Language Teaching, John Wiley \& Sons, Inc., 2018, pp. 1-7.

[16] D.H. Jonassen, Supporting Communities of Learners with Technology: A Vision for Integrating Technology with Learning in Schools, 1995. Retrieved: September 2002. Available: http://www.itd.depaul.edu/website/pages/TrainingEvents/CourseMaterials/jonassen.asp.

[17] O. Tarnopolsky, International English myth and national Englishes reality in EFL: A learner needs perspective. Chapter 7 in Anne Burns (Ed.) Teaching English from a Global Perspective. Case Studies in TESOL Practice Series. Alexandria, VA: TESOL, 2005, pp. 91-98.

[18] D.L. Fried-Booth, Project Work. Oxford: Oxford University Press, 1996.

[19] J. Harmer, The Practice of English Language Teaching (3d ed.), Harlow, Essex: Longman, 2001.

[20] M. Livingstone, Role Play in Language Learning. London: Longman, 1982.

[21] K. Jones, Simulations in Language Teaching. Cambridge: Cambridge University Press, 1982. 
[22] D. Hymes, Foundations in Sociolinguistics. An Ethnographic Approach. Philadelphia: University of Pennsylvania Press, 1974.

[23] L. Damen, Culture Learning: The Fifth Dimension in the Language Classroom. Reading, MA: Addison Wesley Publishing Company, 1987.

[24] N.S. Prabhu, Second Language Pedagogy, Oxford: Oxford University Press, 1987.

[25]. T. Pica, Task-based instruction, in: N. van Deusen-Scholl, N.H. Hornberger (Eds.), Encyclopedia of Language and Education, Vol. 4: Second and Foreign Language Education. New York, NY: Springer, 2007, pp. 71-82. 